\title{
Use of program and target planning for increase in level of traffic safety
}

\author{
Viktor Korchagin ${ }^{1}$, Anatoly Pogodaev ${ }^{1}$, Sergej Ljapin ${ }^{1 *}$, and Viktorija Konovalova ${ }^{1}$ \\ ${ }^{1}$ Lipetsk State Technical University, 398600 Lipetsk, Russia
}

\begin{abstract}
In work it is offered to minimize damage from the happened road accidents due to application of program and target planning for all sociallynaturally-economic transport system, the providing merging of the services and organizations participating in mitigation of consequences of road accident in a subsystem of mitigation of consequences of road accident and increase in effective management of this subsystem due to rationalization of the offered "tree of the purposes".
\end{abstract}

\section{Introduction}

Ensuring the safety of road traffic in road transport is recognized in the Russian Federation as one of the most important global tasks facing the society and the state, which has the most important economic, social and demographic significance. Annually in Russia there are more than 200 thousand road accidents, in which about 27 thousand people die and up to 250 thousand are injured. Accident on the highways causes immense material and moral damage to society as a whole, and to individual citizens. Road traffic injuries accompanying most emergency situations lead to the exclusion of people of working age from the sphere of production. Children are dying and becoming disabled - the strategic potential of society, our future. At the same time, the economy of the country bears both direct and indirect losses. In Russia, the total socio-economic damage from the consequences of road accidents is estimated at about 1 trillion rubles per year $[1,14,15]$.

\section{Material and methods}

It should be noted that all the losses listed depend not only on the number of road accidents (crashes) and their characteristics, but also on how quickly services begin to work to eliminate the consequences of accidents, what resources they have at the same time, what actions and operations they perform, what random events accompany this process. It is necessary to exert all possible efforts to reduce the number of accidents and the amount of damage from their impact. To solve this problem is proposed on the basis of the programtarget approach and the developed conceptual model of combining the services and organizations involved in the elimination of the consequences of accidents in the sub-system for the elimination of consequences of an accident that is an integral part of an open self-

* Corresponding author: lyapinserg2012@yandex.ru 
developing socio- environment-economic and transport system [2, 4]. In our opinion, subsystems of the national system for the organization of road safety should include: a subsystem for preventing the occurrence of road accidents and a subsystem for the elimination of the consequences of road accidents. Let us consider in more detail the last subsystem.

The purpose of the work: reducing the levels of accidents and injuries; minimization of damage from road accidents on the basis of the implementation of the developed conceptual model of the subsystem for the elimination of the consequences of road accidents. The main idea of the concept is to unite all the resources: financial, logistic, informational, social and other, into an open, self-developing transport system, aimed at achieving an effective organization of the management of the object of research through intellectual capabilities, creating a single information and switching network linking information sources, decisionmakers and performers[3]. This ensures that all the persons involved in the process of eliminating the consequences of an accident are quickly brought to the necessary objective information about the actual situation. The application of the concept makes it possible to provide quick control of dispersed elements, their self-synchronization. The subsystem of liquidation of consequences of road and transport incidents, having a certain set of resources with unambiguous characteristics, interacts with another subsystem of the socio-environment and economic system, which is made up by the victims of the road and transport accident: people, vehicles, road, external and surrounding environment, let's call it PVRE (peoplevehicles-road-environment) [5-7, 9], Fig. 1.

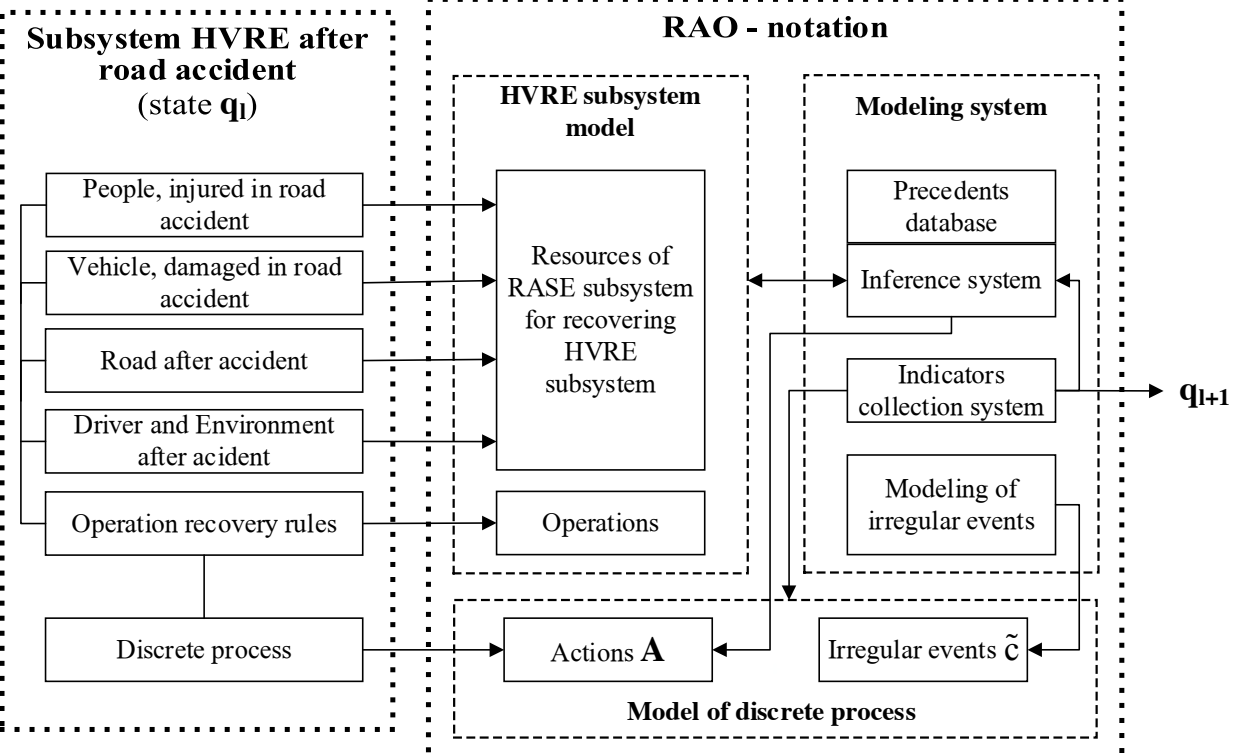

RA - road accident; RAO - "Resources-Actions-Operations" methodology; RASE - subsystem of road accidents subsequences elimination; HVRE - subsystem "Human-Vehicle-Road-Environment"

Fig. 1. A conceptual view model of the subsystem of liquidation of consequences of road accidents.

To introduce the model of the impact of the subsystem for the elimination of the consequences of road accidents on the subsystem "People-vehicles-road-environment" it is proposed to use the "resources-action-operation" method proposed by prof. V.V. Emel'yanov [12] in the study of complex discrete systems and processes occurring in them. As the development of this method, when choosing the algorithm for managing the subsystem for the elimination of the consequences of road accidents, if events occur in it, a constantly 
updated database of precedents and the PATTERN technique (PATTERN - Planning Assistence Through Technical Evaluation of Relevance Numbers - realizing the ideas of program-targeted planning and forecasting, which allow the most rational distribution of limited resources, in order to link the goals formed, as a rule, in a general form, and specific options for allocating resources to a single program $[8,10,11]$. The methodology is based on the procedure for constructing scenarios represented by hierarchical graph models, called the "relevance tree", based on the principles of deductive logic by dividing the problem into subproblems, from one level of the hierarchy to another [10]. The PATTERN technique allows to estimate the dynamics of achievement of goals in the subsystem "People-vehiclesroad-environment" after the road accident on the basis of its initial state $q_{i}$ and the scenario vector of the medium's behavior for the selected time interval. The Pattern method has an established logical structure, which consists of fourteen elements [16, 17]:

- Definition of the object of study.

- Nomination, justification and application of working hypotheses on the concept of relationships and in-object laws.

- Development of a scenario plan.

- Definition of the formulation of the research task and the forecast report.

- Analysis of decomposition architecture.

- Formulation of goals.

- Reconciliation and approval of the architecture with internal ("target tree") and external links (a set of local parameters).

- Application of questionnaires.

- Statistical analysis of the results of the questionnaire.

- Quantifying the hierarchy architecture.

- Confirmation of the hypothesis of the study by a special method.

- Detailing the procedures for sharing responsibility for resources.

- Linking the responsible resources to the "Target Tree".

- Application of expert procedures for assessing the distribution of responsibilities.

All elements of the Pattern system included in the "Tree of Goals" are subject to a thorough assessment of their relative importance. Its application occurs from the top down the hierarchy according to the accepted scenario.

\section{Theory}

The proposed approach allows us to formulate a deeply echeloned list of project objectives with synthesized scales of these goals that characterize various aspects of the significance of the results. Thus, in the implementation of "actions" in the resource-action model, the decision-makers receive a logical basis for allocating budgets and other resources to the "target tree" elements, based on the estimated and calculated weight values and the most likely scenario of developments in the subsystem.

The scenario is predicted by the person making the decision heuristically, with each event being assigned a weight and the probability that it will occur. On the basis of these weights and probabilities, the decision-maker assesses the likelihood of developing an appropriate scenario and selects the most likely for future work [13].

On their basis, a "tree of goals" is compiled. Fig. 2, Table 1. 


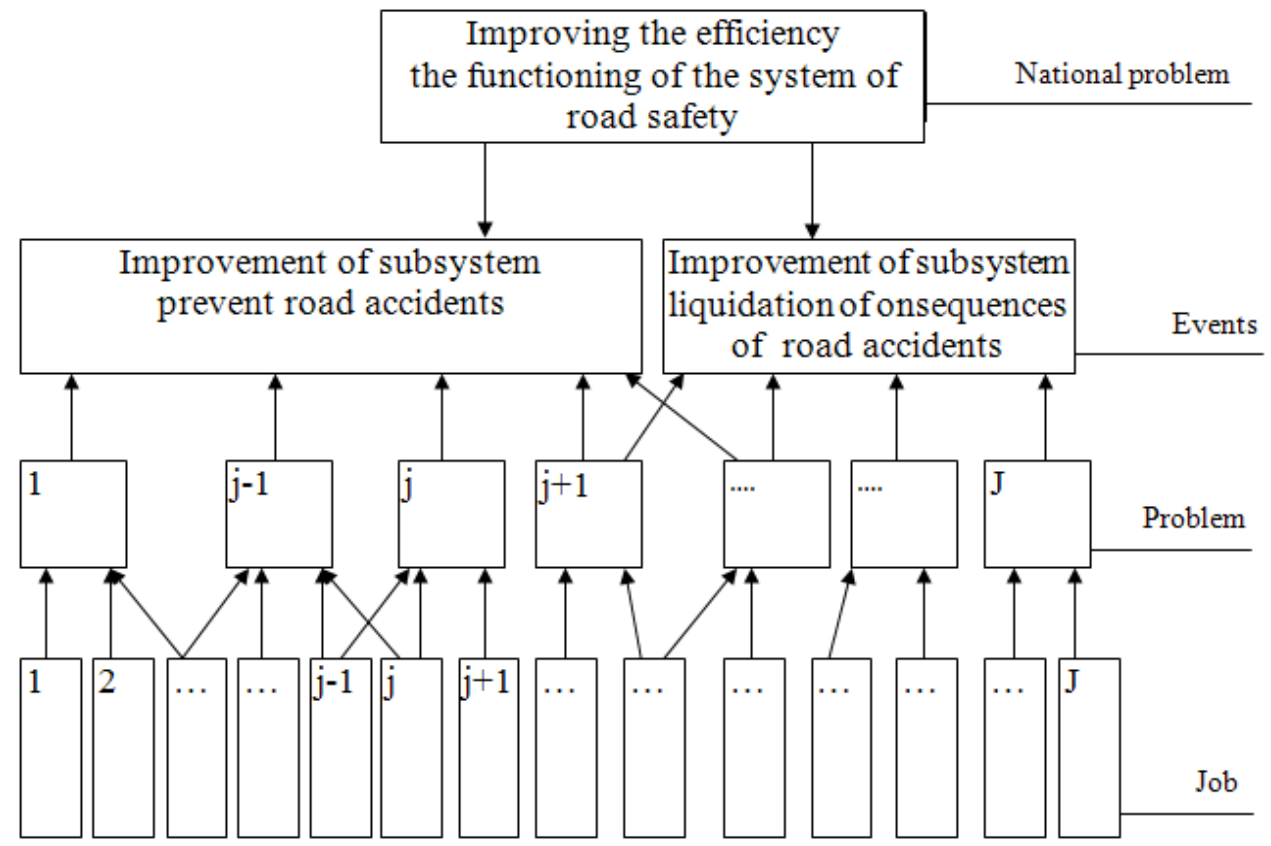

Fig. 2. The tree of the objectives of the solution to the problem "Improving the efficiency of the road safety system".

For each level $n(n=1, N)$ of the goal tree, criteria are formed $\alpha, \beta, \gamma, \ldots v$ with weights $w^{\alpha}, w^{\beta}, \ldots, w^{v}$ and relative weights $s_{j}^{\alpha}, s_{j}^{\beta}, \ldots, s_{j}^{v}$ element $j(j=1, J)$ of level $n$ for criterions $\alpha, \beta, \gamma, \ldots \nu$, being expert estimates of elements of this level.

Uniformity of the results is ensured by two normalizing logical conditions:

$$
\sum_{\alpha=1}^{v} w^{\gamma}=1 ; \sum_{j=1}^{J} s_{j}^{\gamma}=1
$$

Three coefficients are introduced: relative importance $r_{n}^{\gamma}$, state and development time ("state - time") $r_{S}$, mutual utility (mutual influence) $r_{m}$.

$$
r_{n}^{\gamma}=\sum_{\alpha}^{v} w_{\gamma} s_{j}^{\gamma} ; \sum_{j=1}^{J} r_{n}^{\gamma}=1
$$

The coefficient $r_{S}$ characterizes (statically) the degree of readiness of the development, and $r_{m}$-the effect of achieving certain goals on the results of achieving other goals.

On the basis of the given coefficients, the coefficients of importance of the level and the tree as a whole are calculated (this allows comparing the estimates of different trees in the study of several scenarios), table 2 . 
Table 1. Tasks and tasks for the implementation of activities on "Improving the performance of the road safety system"

\begin{tabular}{|c|c|c|}
\hline Activities & Tasks & Assignments \\
\hline $\begin{array}{l}\text { Improvement of the } \\
\text { subsystem } \\
\text { preventing } \\
\text { occurrence of road } \\
\text { accidents }\end{array}$ & $\begin{array}{l}\text { 1. Improvement of the regulatory, legal, } \\
\text { methodological and organizational foundations } \\
\text { of the traffic safety management subsystem } \\
\text { 2. Organization-planning and engineering } \\
\text { measures to improve the organization of traffic } \\
\text { and pedestrians. } \\
\text { 3. Increase of legal consciousness and } \\
\text { prevention of dangerous behavior of road users } \\
\text { 4. Increasing the requirements for active safety } \\
\text { of vehicles and their technical condition. }\end{array}$ & \\
\hline $\begin{array}{l}\text { Improvement of the } \\
\text { subsystem for the } \\
\text { elimination of the } \\
\text { consequences of road } \\
\text { accidents }\end{array}$ & $\begin{array}{l}\text { 1. Improvement of the regulatory, legal, } \\
\text { methodological and organizational foundations } \\
\text { of the subsystem for the elimination of the } \\
\text { consequences of road accidents. } \\
\text { 2. Creation of unified control center for the } \\
\text { subsystem for the elimination of the } \\
\text { consequences of road accidents accompanying } \\
\text { the process at all stages, and its integration with } \\
\text { regional structures: the Ministry for Emergency } \\
\text { Situations, the Ministry of Internal Affairs, } \\
\text { health, roads and transport, ecology and natural } \\
\text { resources, insurance companies. } \\
\text { 3. Higher requirements for passive safety of } \\
\text { vehicles. }\end{array}$ & $\begin{array}{l}\text { 1. Identified by regional } \\
\text { programs to improve road } \\
\text { safety. } \\
\text { 2. Interaction of federal } \\
\text { authorities with the regions } \\
\text { and coordination of efforts to } \\
\text { implement the federal } \\
\text { program and regional } \\
\text { programs. } \\
\text { 3. Certification of vehicles } \\
\text { 4. Combining federal funds } \\
\text { and funds of the regions in } \\
\text { financing the planned } \\
\text { program activities. }\end{array}$ \\
\hline
\end{tabular}

Table 2. The matrix for determining the coefficients of relative importance of the elements at the level $n$.

\begin{tabular}{|c|c|c|c|c|c|c|}
\hline \multirow{2}{*}{$\begin{array}{c}\text { Criteria for improving road } \\
\text { safety }\end{array}$} & \multirow{2}{*}{$\begin{array}{l}\text { Weight of } \\
\text { criterion }\end{array}$} & \multicolumn{5}{|c|}{ Level elements } \\
\hline & & 1 & 2 & $\ldots$ & $j$ & $\bar{J}$ \\
\hline $\begin{array}{l}\alpha-\text { Reduction in the rate of growth } \\
\text { in the number of road accidents }\end{array}$ & $w^{\alpha}$ & $s_{1}^{\alpha}$ & $s_{2}^{\alpha}$ & $\cdots$ & $s_{j}^{\alpha}$ & $s_{J}^{o}$ \\
\hline $\begin{array}{l}\beta \text { - Reducing the severity of the } \\
\text { consequences of road accidents }\end{array}$ & $w^{\beta}$ & $s_{1}^{\beta}$ & $s_{2}^{\beta}$ & $\ldots$ & $s_{j}^{\beta}$ & $s_{J}^{\prime}$ \\
\hline $\begin{array}{l}\text { Reduction in the rate of increase in } \\
\text { the number of wounded } \\
\text { Decrease in the rate of increase in } \\
\text { the number of deaths }\end{array}$ & $\cdots$ & $\cdots$ & $\ldots$ & $\cdots$ & $\ldots$ & .. \\
\hline $\begin{array}{l}\gamma-\text { Reducing transport risk (the } \\
\text { number of deaths per } 10 \text { thousand } \\
\text { vehicles) }\end{array}$ & $w^{\gamma}$ & $s_{1}^{\gamma}$ & $s_{2}^{\gamma}$ & $\cdots$ & $s_{j}^{\gamma}$ & $s_{J}^{\gamma}$ \\
\hline $\begin{array}{l}v-\text { Reducing social risk (the } \\
\text { number of deaths per } 100 \text { thousand } \\
\text { of the population) }\end{array}$ & $w^{v}$ & $s_{1}^{v}$ & $s_{2}^{v}$ & $\cdots$ & $s_{j}^{v}$ & $s_{J}^{v}$ \\
\hline & & $r_{n}^{1}$ & $r_{n}^{2}$ & & $r_{n}^{j}$ & $r_{n}^{J}$ \\
\hline
\end{tabular}

\section{Results and discussion}

The use of the PATTERN methodology to solve problems of scientific and technical forecasting and planning in the field of improving the efficiency of the system of organizing road safety makes it possible to identify promising avenues for solving this problem, on 
which the main efforts should be concentrated, and the comparative significance of the proposed solutions should be assessed. The conceptual model is oriented not only to the effective management of the available resources of the subsystem for the elimination of the consequences of road accidents, but also to the ability of the subsystem to adapt quickly to a rapidly changing environment and to transfer the functions of strategic and operational control to managed objects and subjects in accordance with the requirements of the evolving environment. At the same time, monitoring results should be analyzed in real time by an intelligent analytical system capable of combining sometimes disparate little-information flows of primary information into a complex multi-level forecast generated on the basis of mathematical models and heuristic methods [4].

The consequences of road accidents tend to be combined, therefore, in the formation of goals and strategies for their elimination, a wide range of impacts on the elements of the subsystem "People - Vehicles - Road - Environment", the stability characteristics of the elements of this subsystem, available resources of the subsystem elimination of the consequences of road accidents, mentality of the head. After choosing the available measures for the elimination of the consequences of road accidents, it is necessary to assess how effectively they will be consistent with the principle of concentration of efforts and to rank them according to socio-economic criteria, as well as in others, including not only economic indicators.

This leads the decision maker to a deeper understanding of the situation that arose after the road accident, a better understanding of the consequences of his choice, the ability to predict the results of his actions, and achieve quick management in the course of implementing the selected activities.

In the methodological plan, the subsystem for eliminating the consequences of road accidents is built on the basis of the developed concept of the intellectual model, which includes subsystems: information, monitoring and resource. Interactions of the elements of the structure of the subsystem for the elimination of the consequences of road accidents are complex and multifaceted, they form the environment in which the tasks are accomplished to achieve the main goal and affect both the physical spheres and the spheres that form the adoption of scientifically grounded solutions and ensure their effective implementation.

The reported study supported by the Russian Science Foundation within the project 18-71-10034.

\section{References}

1. P.A. Potseluev, Socio-economic methods of evaluation of road accident-caused damage in Russian economic safety provision mechanism. Moscow, $22 \mathrm{p}$.

2. V. A. Korchagin, A. N. Novikov, S. A. Lyapin, V. A. Konovalova, Process modelling in the subsystem of traffic accident consequence iquidation, International Journal of Pharmacy \& Technology, 8(3), pp. 15262-15270 (2016)

3. E.A. Trakhtengert, Network-centric methods of computer-aided counteracting to accidents and risks, Large systems management, pp. 41 pp. 162-248 (2013)

4. V.A. Korchagin, S.A. Ljapin, V.E. Klyavin, V.V. Sitnikov, Improvement of road traffic safety on the basis of accidence analysis and road accidents modeling, Fundamental survey, 6(2), pp. 251-256 (2015)

5. V.A. Korchagin, S.A. Lyapin, J.N. Rizaeva, V.A. Konovalova, Subsystem of Road Accident Consequences Elimination. Methodology of Subsystem Efficiency Improvement, Transportation Research Procedia, 20, pp. 316 - 320 (2017)

6. V.A. Korchagin, A.N. Novikov, S.A. Lyapin, J.N. Rizaeva, I.A. Novikov, Complex Self-Developing Transport Systems. International Journal of Pharmacy \& Technology, 
8(3), pp. 15253-15261 (2016)

7. V.A. Korchagin, S.A. Lyapin, V.A. Konovalova, Mathematical model of negotiating solutions in the supply chain "factory - regional dealer", Drive higher education institutions Chernozem, 1(31), pp. 43-48 (2013)

8. N.A. Korgin, V.O. Korepanov, Solving of efficient resources allocation task on the basis of Groves-Ledyard mechanism in condition of transferable utility, Large systems management, 46, pp. 216-265 (2013)

9. V.A. Korchagin, S.A. Lyapin, V.E. Klyavin, V.V. Sitnikov, New approaches to the modeling of work of road service, Organization and road safety: mater. int. scientific.pract. Conf. Tyumen, pp. 226-230 (2017)

10. V.A. Korchagin, A.K. Pogodaev, V.E. Klyavin, V. A. Suvorov, Scientific and practical method of improving road safety, Autotransport company, 11, pp. 19-22 (2016)

11. V.A. Korchagin, A.K. Pogodaev, V.E. Klyavin, V.V. Sitnikov, Scientific basis of the expert system of road safety, Transportation Research Procedia, 20, pp. $321-325$ (2017)

12. V.V. Yemelyanov, Theoretical basis and methods of intellectual models development for decision making during operation management and modeling of CIM. Moscow: Moscow State Technical University of N.E. Bauman, 29 p. (1995)

13. A.K. Yenaleyev, Appropriate coordinated mechanisms in active systems and contracts theory task, Large systems management, 49, pp. 167-182 (2014)

14. G.M. Kaziakhmedov, P.A. Potseluev, Socio-economic aspects of the consequences of road accidents in Russia. Regional economy: theory and practice, 7, pp. 124-129 (2007)

15. M.M. Ziganshin, Program-targeted approach to the issue improving road safety, Science and practice, 1 (66), pp. 47-50 (2016)

16. I.I. Kovalenko, A.V. Shved, Methods of expert evaluation of scenarios: tutorial, Nikolaev: Petro Mohyla Black Sea National University (2012)

17. E.G. Barshhevskij, G.N. Rumjanceva, V.D. Chertovskoj, Theoretical foundations of automated control. Problems and prospects: tutorial - SPb.: SPGUVK, 398 p. (2011) 